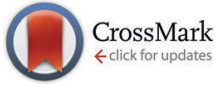

Cite this: J. Mater. Chem. C, 2015, 3, 12484

Received 30th January 2015, Accepted 12th October 2015

DOI: $10.1039 / \mathrm{c} 5 \mathrm{tc00307e}$

www.rsc.org/MaterialsC

\section{The band structure of graphene oxide examined using photoluminescence spectroscopy $\dagger$}

\author{
H. F. Liang, ${ }^{\star a b}$ C. T. G. Smith, ${ }^{b}$ C. A. Mills ${ }^{b c}$ and S. R. P. Silva*b
}

Photoluminescence (PL) spectra have been used to elucidate the band structure of graphene oxide (GO) reduced in aqueous solution. The GO reduction is measured in situ via the identification of four $\mathrm{PL}$ peaks produced from GO solutions with different concentrations. Using corresponding UV-visible and photoluminescence excitation (PLE) spectroscopy, and on progressing from high energy to low energy transitions, the four PL peaks are identified as $\sigma-\sigma^{*}$ and $\pi-\pi^{*}$ transitions, a $\pi$ band tail due to oxygen localized states, and a $\pi$ band tail due to trapped water, respectively. The labeling of the band structure has been used to challenge the prevailing assignation of the low energy transitions, reported in the literature, to molecular $\sigma-\sigma^{*}$ and $\pi-\pi^{*}$ transitions alone.

\section{Introduction}

Due to its attractive electrical and optical properties, ${ }^{1-3}$ graphene oxide (GO) has potential for applications in electronics ${ }^{4,5}$ and optoelectronics, ${ }^{6-8}$ and in particular photodetectors. Special attention has been focused on GO's complex band structure but, despite this, significant differences in experiment and theoretical band structures have been reported. ${ }^{9-14}$ This has also been mirrored in the experimental band structure obtained from photoluminescence (PL), where notable differences; ${ }^{15-24}$ and even contradictory values for physical properties, such as band gap and resistivity have been reported. ${ }^{25,26}$

To date, researchers have typically observed PL peaks for GO located in the blue (around $430 \mathrm{~nm}[2.88 \mathrm{eV}]$ ) and red regions (around $580 \mathrm{~nm}[2.14 \mathrm{eV}]$ ) of the visible spectrum. ${ }^{16-18,20}$ The low energy PL peak has been attributed to microstructure and defect states induced by oxygen. ${ }^{16,17,19-21}$ With reduction this peak blue-shifts and even disappears, ${ }^{16,20}$ with a new peak appearing in the blue region of the spectrum due to recovery of the $\mathrm{sp}^{2}$ carbon network. ${ }^{16,19-21}$

However, the band gap of as-prepared GO has been determined to be approx. $3.5 \mathrm{eV}$, suggesting that the corresponding PL peak should be positioned at $354 \mathrm{~nm}$ which is somewhat different from that previously reported experimentally. ${ }^{27}$ The GO band gap and resistivity are also found to decrease with reduction ${ }^{25-27}$

\footnotetext{
${ }^{a} X i$ 'an Technological University, BOX 277, No. 95 Jinhua North Road, Xi'an City, 710032, P. R. China. E-mail: hfliang2004@gmail.com

${ }^{b}$ Advanced Technology Institute, University of Surrey, Guildford, Surrey, GU2 7XH, UK. E-mail: s.silva@surrey.ac.uk

${ }^{c}$ Advanced Coatings Group, Surface Engineering Department, Tata Steel Research Development and Technology, Swinden Technology Centre, Rotherham, S60 $3 A R, U K$

$\dagger$ Electronic supplementary information (ESI) available. See DOI: 10.1039/c5tc00307e
}

which should cause the PL peak to red-shift, opposite to the reported PL results. ${ }^{16,20}$ The reduction has been confirmed as being due to the removal of oxygen groups ${ }^{27}$ with a consequent conversion of $\mathrm{sp}^{3}$ carbons to $\mathrm{sp}^{2}$.

Here, PL experiments have been completed which allow us to form a clearer understanding of the as-produced GO band structure and the effects on the band structure during reduction. Four PL peaks, at $4.04 \mathrm{eV}$ and $3.44 \mathrm{eV}$, a broad peak between 3.31 and $2.82 \mathrm{eV}$, and at $2.14 \mathrm{eV}$, have been identified for as-produced GO, assigned to $\sigma-\sigma^{*}$ and $\pi-\pi^{*}$ transitions, a $\pi$ band tail due to oxygen localized states (including lone electron pair transition), and a $\pi$ band tail due to trapped water, respectively. Relative intensity variations of these peaks are then examined with respect to the reduction process.

\section{Experimental}

\subsection{Aqueous GO solution preparation}

GO was synthesized from graphite using the Hummers and Offeman method. ${ }^{28}$ The as-synthesized GO was suspended in de-ionized water using a sonic bath, resulting in aqueous solutions with concentrations from 0.01 to $0.5 \mathrm{mg} \mathrm{ml}^{-1}$. Part of the resulting GO solution was reduced by a hydrothermal method using a water bath $\left(95^{\circ} \mathrm{C}\right)$ for different time periods. Alternatively, GO solutions with different $\mathrm{pH}$ values were produced by adding sodium hydroxide $\left(\mathrm{NaOH}, 0.1 \mathrm{~mol} \mathrm{~L}^{-1}\right)$ and hydrochloric acid (HCL, 5\% aqueous solution) respectively. Aqueous GO solutions $\left(0.1 \mathrm{mg} \mathrm{ml}^{-1}\right)$ were also prepared containing vitamin $\mathrm{C}\left(0.05 \mathrm{mg} \mathrm{ml}^{-1}\right)$. After standing for 96 hours at room temperature, the solution color changed from brown to black, and sediment could be observed at the bottom of 
the bottle. Aliquots of the supernatant were then decanted for PL measurement.

For comparison, GO power was directly reduced by vacuum thermal annealing at temperatures of 50 and $200{ }^{\circ} \mathrm{C}$, respectively. The reduced graphene oxide was then suspended in de-ionized water for PL testing.

\subsection{GO characterization}

Ultraviolet-visible (UV-vis) absorption spectra (185-1200 nm [1.03-6.70 eV], $0.5 \mathrm{~nm}$ resolution) were acquired using UV-vis spectroscopy (Varian Cary 5000 UV-vis-NIR absorption spectrometer, Agilent Technologies, USA), utilizing quartz cuvettes with optical path lengths of $10 \mathrm{~mm}$. PL and Photoluminescence excitation (PLE) spectra were obtained at different excitation/ measurement wavelengths (1.0 $\mathrm{nm}$ resolution) using a spectrophotometer (Varian Cary Eclipse Fluorescence Spectrophotometer, Agilent, USA), where a xenon lamp was used to excite the GO sample and a red-sensitive photomultiplier tube was used for detection. The excitation and emission slit widths were both $10 \mathrm{~nm}$, and the detector applied voltage was $700 \mathrm{~V}$.

XPS (X-ray photoelectron spectroscopy, K-Alpha, Thermo Fisher Scientific) was undertaken using Aluminium K $\alpha$ X-rays, with beam energy, beam spot size and beam current density of $1486.60 \mathrm{eV}, 400 \mu \mathrm{m}$ and $4.778 \mathrm{~A} \mathrm{~cm}^{-2}$, respectively, resulting in a spectral resolution of approx. $0.5 \mathrm{eV}$. The XPS data were collected under scanning mode and analyzed in Thermo Scientific Advantage 4.51 software, respectively. A peak fitting process was performed where the linear background was first deducted from the original XPS data, after which the spectra were aligned using the $\mathrm{C}-\mathrm{C}$ bond energy (284.6 eV), and then fitted using a Gauss peak.

Thermogravimetric analysis (TGA) was carried out under an ambient air environment at temperatures from ambient to $900{ }^{\circ} \mathrm{C}$, with $5{ }^{\circ} \mathrm{C}$ measurement intervals (Q500 TGA, TA Instruments, USA). Raman spectra (Renishaw Systems 2000 Raman microscope) were recorded using a green laser (514 nm, $30 \mathrm{~mW})$ at $2 \mathrm{~cm}^{-1}$ resolution.

\section{Results and discussion}

\subsection{PL, PLE and absorption spectra}

Fig. 1 shows the PL (5.39 eV excitation energy) and PLE (3.18 eV measurement energy) spectra for as-prepared GO solution, which are superimposed with the corresponding absorption spectrum. Four PL peaks can be observed at 4.04 and $3.44 \mathrm{eV}$, a broad peak between 3.31 and $2.82 \mathrm{eV}$ (including a shoulder at $2.95 \mathrm{eV}$ ), and at $2.14 \mathrm{eV}$. Excitation energy-dependent PL experiments (ESI, $\dagger$ Fig. S1 and S2) also confirm the presence of these four peaks. Two corresponding peaks can be seen in the PLE spectrum, a shoulder peak at 5.39, and $4.20 \mathrm{eV}$. A third peak may be inferred by the increasing slope of the curve up to $6.20 \mathrm{eV}$. The fourth peak could not be seen due to a very low PL efficiency. The peak observed at $3.61 \mathrm{eV}$ is the Raman peak for water. The absorption curve also reveals three peaks in similar positions to those found in the PLE spectrum. Finally, a long absorption tail from $3.88 \mathrm{eV}$ to low energies can be observed.

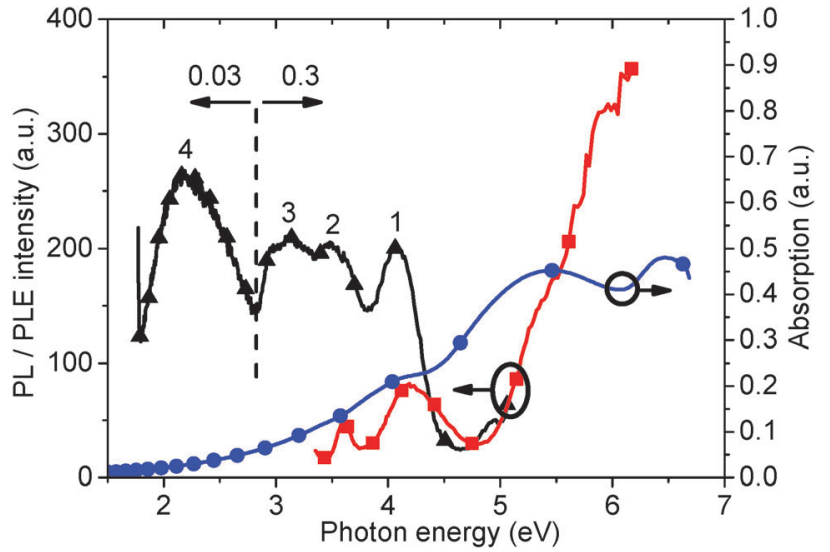

Fig. $1 \mathrm{PL}$ (black triangles, excitation energy = $5.39 \mathrm{eV}$ ), PLE (red squares, measurement energy $=3.18 \mathrm{eV}$ ) and absorption spectrum (blue circles) of as-prepared GO from aqueous solution. GO solutions of two different concentrations $\left(0.03\right.$ and $\left.0.3 \mathrm{mg} \mathrm{ml}^{-1}\right)$ were examined to obtain $\mathrm{PL}$ peaks in different regions of the ultraviolet/visible spectrum, below and above $2.85 \mathrm{eV}$ respectively. Absorption and PLE were acquired using $0.03 \mathrm{mg} \mathrm{ml}^{-1}$ solution.

The PL spectrum is divided into two sections corresponding to PL measurement using different GO solution concentrations below $2.85 \mathrm{eV}$ using $0.03 \mathrm{mg} \mathrm{ml}^{-1}$ solution, and above $2.85 \mathrm{eV} \mathrm{nm}$ using $0.3 \mathrm{mg} \mathrm{ml}^{-1}$ solution respectively. The graph shows the recorded data with no normalization required to align the intensity of the plots recorded above and below $2.85 \mathrm{eV}$.

Generally, previous work has only reported two PL peaks, whereas here we report on four peaks. Fig. 2 shows the variation of the fourth PL peak $(2.14 \mathrm{eV})$ with increasing solution concentration. The peak is seen to effectively disappear for GO solution concentrations below $0.03 \mathrm{mg} \mathrm{ml}^{-1}$. At higher concentrations, the peak at $1 \mathrm{mg} \mathrm{ml}^{-1}$ can be seen to be lower intensity than that of the 0.5 and $0.25 \mathrm{mg} \mathrm{ml} \mathrm{m}^{-1}$ concentrations, and displays a slight red-shift. This suggests that the optimum concentration for observing the $2.14 \mathrm{eV}$ peak in PL is about $0.5 \mathrm{mg} \mathrm{ml} \mathrm{m}^{-1}$,

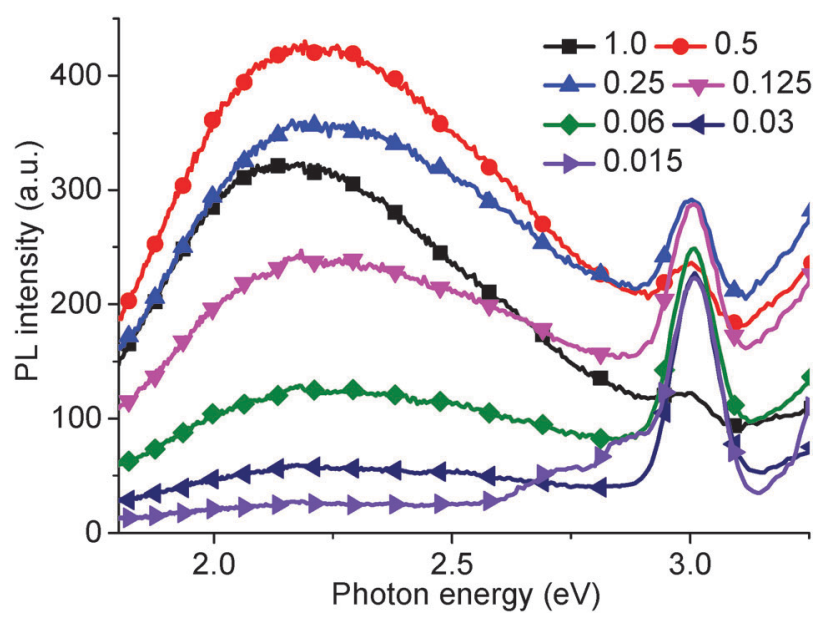

Fig. $2 \mathrm{PL}$ intensity (excitation energy $=3.444 \mathrm{eV}$ ) in the red region of the visible spectrum for different aqueous GO solution concentrations (0.015-1.0 $\left.\mathrm{mg} \mathrm{m}^{-1}\right)$. 
which gives a good balance between the appropriate absorption for excitation and scattering for emission.

However, it is impossible to observe the other PL peaks (at $4.04 \mathrm{eV}, 3.44 \mathrm{eV}$, and a broad peak between $3.31 \mathrm{eV}$ and $2.82 \mathrm{eV}$ ) using this high concentration solution. Typically, to observe these high energy peaks, the concentration must be decreased (Fig. 3), and an effective PL signal can usually be achieved by tuning the solution absorbance excitation wavelength to approx. 0.1 a.u. Similarly, as-produced GO displays an increase in absorption with wavelength, as shown in Fig. 4. Thus, in order to resolve all the peaks in the PL spectrum, the different solution concentrations were applied. Previously, only the two low energy PL peaks were observed due to the use of higher solution concentrations. ${ }^{20,21,24}$

The absorption peak at $5.39 \mathrm{eV}$ (Fig. 4) has been confirmed as being due to the $\pi-\pi^{*}$ band transition. ${ }^{19}$ The calculated band gap, taken from the slope of the absorption curve, is

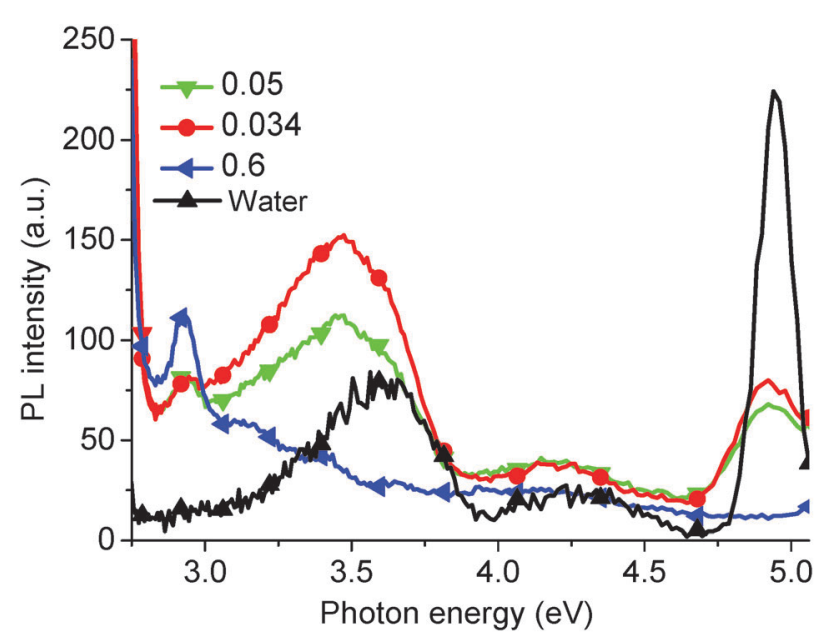

Fig. 3 PL spectra (excitation energy $=5.39 \mathrm{eV}$ ) for increasing GO solution concentrations $\left(0.034,0.05,0.6 \mathrm{mg} \mathrm{ml}^{-1}\right)$ after hydrothermal reduction for $5 \mathrm{~min}$. For comparison, the PL spectrum of water is given.

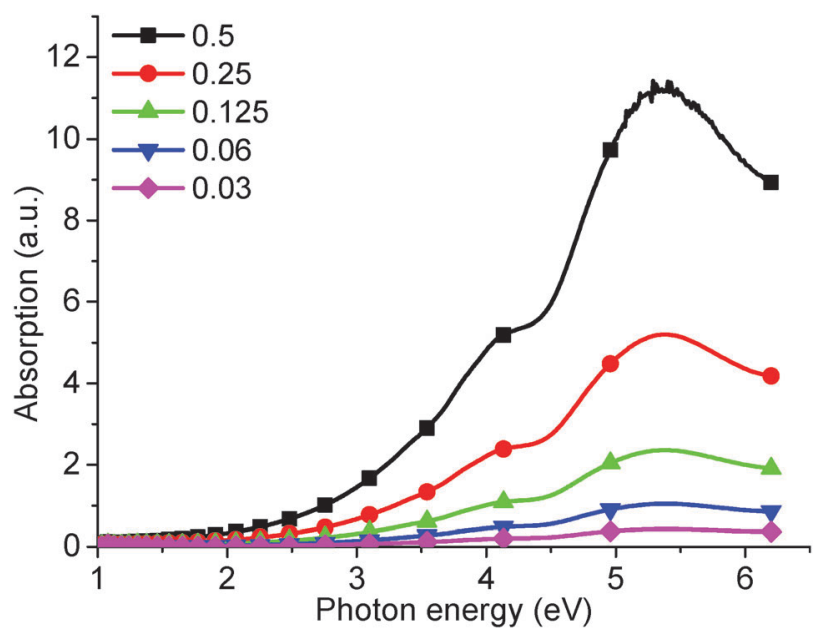

Fig. 4 UV-visible absorption of as-produced GO from increasingly concentrated aqueous solution: $0.03,0.06,0.125,0.25,0.5 \mathrm{mg} \mathrm{m}^{-1}$. about $3.5 \mathrm{eV}^{27}$ This is in close agreement with the $3.44 \mathrm{eV}$ PL peak observed in Fig. 1, which is consequently assigned to the $\pi-\pi^{*}$ band transition.

The UV-visible peak at $6.53 \mathrm{eV}$ (Fig. 1) is reported for the first time in our experiments and is determined to be due to the $\sigma-\sigma^{*}$ transition, similar to that seen in diamond-like carbon/ amorphous carbon films. ${ }^{29,30}$ Attaching oxygen to graphene will convert a planar $\mathrm{sp}^{2}$ carbon to $\mathrm{sp}^{3}, 31,32$ and produces a corresponding absorption peak at higher energy than the $\pi-\pi^{*}$ band transition. The PL peak at $4.31 \mathrm{eV}$ (Fig. 1), at a higher energy than the corresponding $\pi-\pi^{*}$ transition $(3.44 \mathrm{eV})$, was therefore assigned to a $\sigma-\sigma^{*}$ transition. This has been fully discussed using multiple analytical methods on $\alpha$-C thin films. ${ }^{33}$

The absorption shoulder at $4.20 \mathrm{eV}$ (Fig. 4), corresponding to the $2.95 \mathrm{eV}$ PL peak (Fig. 1), is determined to be due to a transition from the oxygen lone electron pair to the carbon $\pi$ band. ${ }^{34}$ Finally, the long absorption tail was assigned to the presence of localized states on the oxygen group and trapped water, ${ }^{19,34}$ and corresponds to the broad PL peak between $3.31 \mathrm{eV}$ and $2.82 \mathrm{eV}$ and the peak at $2.14 \mathrm{eV}$, respectively. We show that the PL peak, at $2.14 \mathrm{eV}$, decreases correspondingly as trapped water is removed; similarly, the broad peak decreases concomitant with the removal of the oxygen. A new peak produced at $2.82 \mathrm{eV}$ after an extensive reduction is shown to be ascribed to states induced by the recovery of micro-sized $\mathrm{sp}^{2}$ carbon sites.

Consequently, comparing the three curves (PL, PLE and absorption), we confirm that the PL peaks at $4.04 \mathrm{eV}, 3.44 \mathrm{eV}$, the broad peak between 3.31 and $2.82 \mathrm{eV}$ including a $2.95 \mathrm{eV}$ peak, and the $2.14 \mathrm{eV}$ peak are due to $\sigma-\sigma^{*}$ and $\pi-\pi^{*}$ transitions, a $\pi$ band tail due to oxygen localized states (including long electron pair transition), and a $\pi$ band tail due to trapped water, respectively. A summary of peak assignations is given in Table 1.

\subsection{Hydrothermal reduction}

In order to support our assignations, PL measurements were carried out on GO solutions lightly reduced using a hydrothermal reduction method (Fig. 5). At high energies (Fig. 5a), the peak at $4.04 \mathrm{eV}$ increased up to $120 \mathrm{~min}$ reduction time, and then decreased at $240 \mathrm{~min}$. The peak at $3.44 \mathrm{eV}$ reached a maximum after 5 min annealing, then decreased, and finally, the broad peak between 3.31 and $2.82 \mathrm{eV}$ decreased after reduction. At lower energies (Fig. 5b), the peak at $2.39 \mathrm{eV}$ decreased with annealing time but did not display any blue shift, observed previously in the literature. ${ }^{16,19,20}$

These peak variations relate to the relative $\mathrm{sp}^{2}$ and $\mathrm{sp}^{3}$ carbon hybridization induced by the removal of oxygen groups and trapped water. With gentle reduction, the oxygen groups have been removed gradually, causing a concurrent increase in $\mathrm{sp}^{2}$ carbon content. Thus, the density of states would decrease in the $\sigma$ band in comparison to the increase in the $\pi$ band states. Based on this, the peak at $4.04 \mathrm{eV}$, corresponding to the $\sigma-\sigma$ transition, should decrease with GO reduction. In fact, in our experiments, the peak at $4.04 \mathrm{eV}$ initially increases (up to $120 \mathrm{~min}$ ). To explain this, we assume that water trapped in the 
Table 1 Peak assignations for the GO samples as a function of peak position in PL, PLE and UV-visible spectra

\begin{tabular}{llll}
\hline Peak position $(\mathrm{eV})$ & & & \\
\hline PL & PLE & UV-visible & Transition \\
\hline 4.05 & $(6.20)$ & 6.53 & $\sigma-\sigma^{*}$ \\
3.44 & 5.39 & 5.39 & $\pi-\pi^{*}$ \\
Broad peak between 3.31 and $2.82 \mathrm{eV}$ & 4.20 & Long absorption tail (including the & Oxygen localized states including lone \\
including the $2.95 \mathrm{eV}$ peak & & shoulder at 4.20 eV) & electron pair- $\pi$ band \\
2.39 & None & Long absorption tail &
\end{tabular}
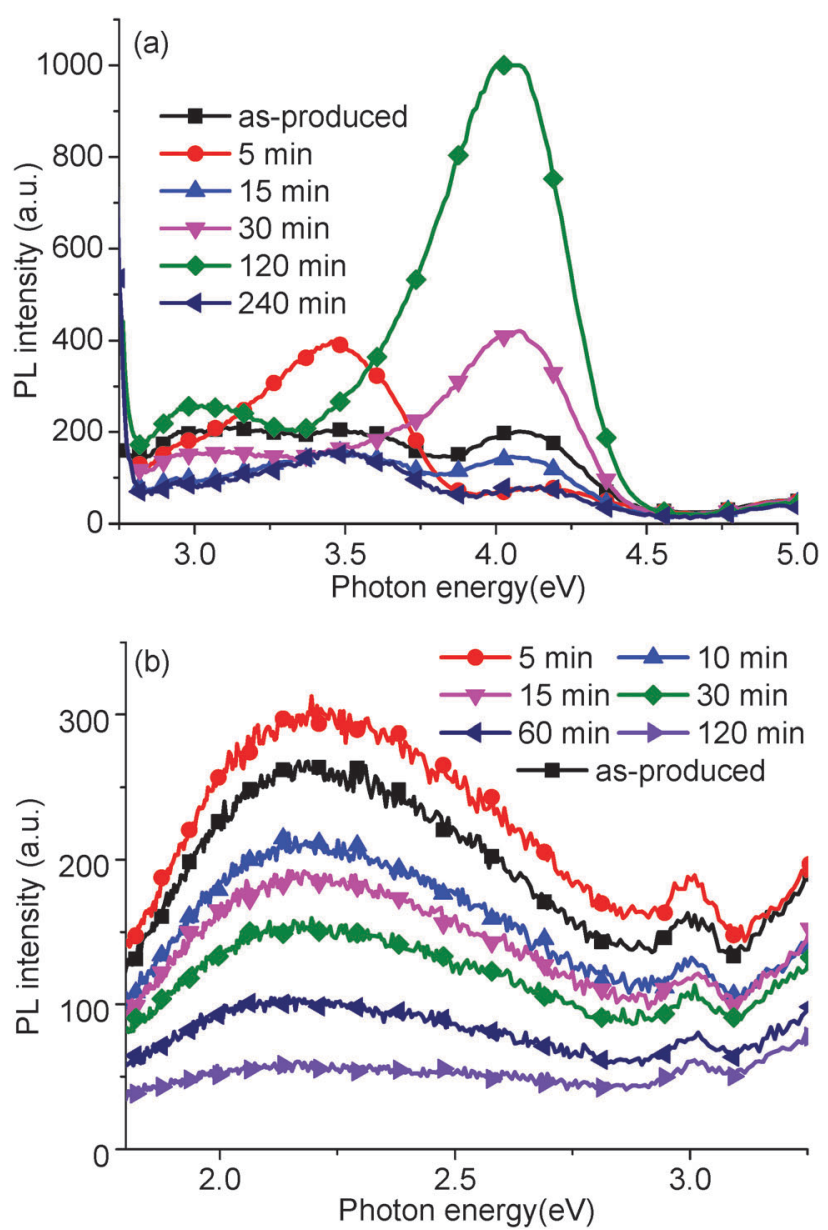

Fig. 5 PL spectrum, recorded using (a) $5.39 \mathrm{eV}$ and (b) $3.44 \mathrm{eV}$ excitation energies, of as-produced $\mathrm{GO}$ and after hydrothermal reduction at $95{ }^{\circ} \mathrm{C}$ with different processing times: 5, 10, 15, 30, 60, 120 and $240 \mathrm{~min}$.

GO structure initially plays a key part in the structure determined by PL.

At $95{ }^{\circ} \mathrm{C}$, trapped water would slowly be removed from the GO structure (Section 3.4 addresses this point further), simultaneously the peaks at $4.04 \mathrm{eV}$ and $2.14 \mathrm{eV}$ increase and rapidly decrease respectively. Thus, trapped water could quench PL in the ultraviolet and contribute to the PL peak at $2.14 \mathrm{eV}$. Previous work has suggested that water can be trapped by hydrogen bonding to hydroxyl and epoxide groups, which will affect the $\mathrm{C}-\mathrm{C}$ bond angle and the length of $\mathrm{C}-\mathrm{C}$ base plane. ${ }^{32,35}$ A possible reason for the quenching of the $4.04 \mathrm{eV}$ peak is that the hydrogen bonding between the trapped water and a GO oxygen group could change the bond angle and length of $\mathrm{sp}^{3}$ carbons on the GO. After $120 \mathrm{~min}$, the peaks at $4.04 \mathrm{eV}, 3.44 \mathrm{eV}$, and the broad peak between 3.31 and $2.82 \mathrm{eV}$ all decreased, resulting in the recovery of $\mathrm{sp}^{2}$ carbons on the reduced GO, and indicated by the dark colour of the GO solution.

The corresponding UV-visible absorption curves (Fig. 6) produced results in agreement with the PL measurements. The absorption peaks at 6.53 and $5.39 \mathrm{eV}$ for the reduced GO produced a similar trend in intensity to that of the 4.04 and $3.44 \mathrm{eV}$ PL peaks, respectively. The absorption shoulder at $4.20 \mathrm{eV}$ disappears at reduction times greater than $120 \mathrm{~min}$, which corresponds to the decreasing PL shoulder at $2.95 \mathrm{eV}$ (see Fig. 5). In addition, the slight red-shift of the $5.39 \mathrm{eV}$ peak and increasing long absorption tail indicate the recovery of $\mathrm{sp}^{2}$ carbon moieties and the removal of oxygen groups. However, the PL peak at $3.44 \mathrm{eV}$ did not increase in intensity, which was in agreement with published results, ${ }^{15,19}$ possibly due to a low PL efficiency of reduced GO.

\section{3. $\mathrm{pH}$ dependent reduction}

In order to further support our results, $\mathrm{pH}$-dependent PL experiments were also performed (Fig. 7) which provides another effective method for tuning the GO structure. ${ }^{23,24}$ Previous work has shown that adding base $(\mathrm{NaOH})$ quenches $\mathrm{PL}$ in the red region of the visible spectrum. ${ }^{23,24}$ Our results corroborate this effect (Fig. 7b), but we also show that the intensities of the high

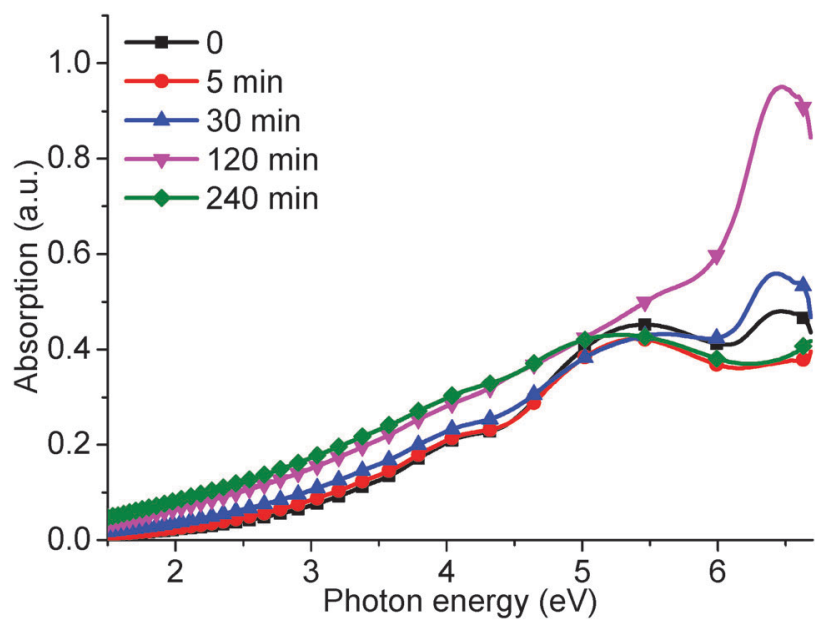

Fig. 6 UV-visible absorption curves for as-produced $\mathrm{GO}$ and subjected to different hydrothermal reduction times: 5, 30, 120, and $240 \mathrm{~min}$. 

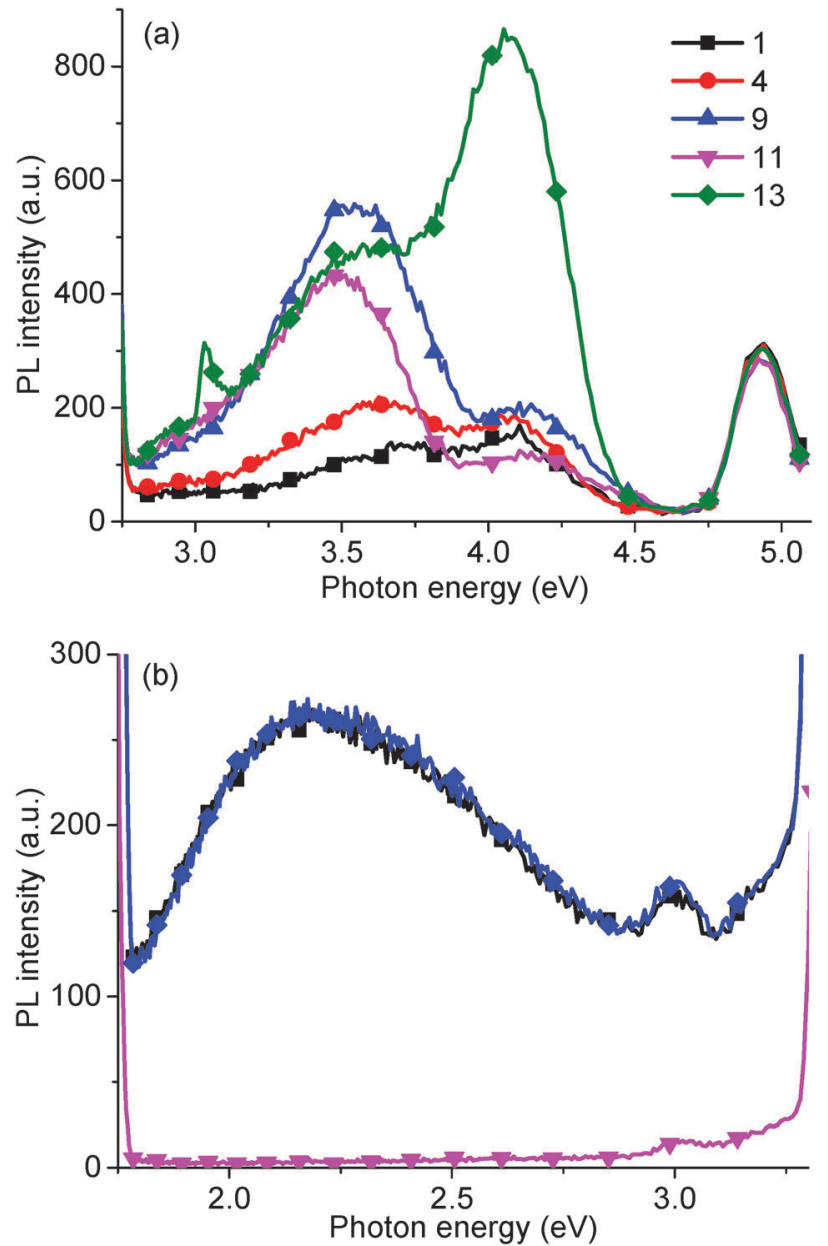

Fig. 7 (a) PL spectra of $\mathrm{GO}$ (excitation wavelength $=5.39 \mathrm{eV}$ ) as a function of $\mathrm{pH}$ at $\mathrm{pH} 1,4,9,11$, and 13 , and (b) PL spectra of GO (excitation wavelength $=3.44 \mathrm{eV}$ ) as a function of $\mathrm{pH}$, when subjected to acid (blue diamonds) and base (purple down triangles) conditions, compared to pristine GO (black circles).

energy 4.04 and 3.44 eV PL peaks are enhanced upon increasing the pH using $\mathrm{NaOH}$ (Fig. 7a).

Obviously, in this case the structure of the GO has been altered, with $-\mathrm{OH}$ and $-\mathrm{COOH}$ rich $\mathrm{GO}$ produced after adding alkali and acid, respectively. ${ }^{24}$ Adding $\mathrm{NaOH}$ provided abundant - $\mathrm{OH}$ groups which attack the $\mathrm{C}-\mathrm{C}$ base plane and open $\mathrm{C}=\mathrm{C}$ bonds to produce $\mathrm{C}-\mathrm{O}$ bonds, which consequently affects the carbon bond angle and length. ${ }^{36}$ This results in the conversion of $\mathrm{sp}^{2}$ carbon atoms to $\mathrm{sp}^{3},{ }^{31}$ causing an increase in the $4.04 \mathrm{eV}$ peak. The addition of the dissociated $\mathrm{Na}^{+}$could potentially dehydrate the GO, removing the trapped water and causing the reduction of the $2.14 \mathrm{eV}$ peak.

Inversely, adding acid removes existing hydroxyl $(-\mathrm{OH})$ groups attached to the GO carbon base plane, resulting in the production of $\mathrm{sp}^{2}$ carbon atoms from their $\mathrm{sp}^{3}$ analogues and the subsequent decrease in the $4.04 \mathrm{eV}$ peak. Alteration of the GO structure in this manner produces PL spectra similar to those associated with the hydrothermal reduction process above, and further suggests that the PL peaks at different wavelengths are due to the corresponding assigned transitions.

\subsection{Evidence for trapped water in the GO structure}

Experiments were undertaken to attempt to prove that the 2.14 eV PL peak was correctly assigned with respect to water trapped in the GO structure. As-synthesized GO powder was annealed in a vacuum chamber $\left(50{ }^{\circ} \mathrm{C}\right.$ for $\left.24 \mathrm{~h}\right)$, and then suspended into de-ionized water for PL testing. Fig. 8 shows the PL spectra, excited at a wavelength of $3.67 \mathrm{eV}$, for a sample annealed at $50{ }^{\circ} \mathrm{C}$ compared to PL spectra of as-produced GO and GO which is reduced at $200{ }^{\circ} \mathrm{C}$. When compared to the PL spectra of as-produced GO, the $2.14 \mathrm{eV}$ peak for GO annealed at $50{ }^{\circ} \mathrm{C}$ disappears. This peak can be attributed to adsorbed water, because at such a low temperature it is unlikely that chemical changes occur in the structure of the GO and that only trapped water is slowly removed. Upon increasing the annealing temperature to $200{ }^{\circ} \mathrm{C}$, a valley appears in the PL spectrum at $2.88 \mathrm{eV}$ due to the removal of oxygen groups from the GO surface (Fig. 8). A corresponding PL peak $(2.88 \mathrm{eV})$ is observed from the GO solution (Fig. 1). Moreover, the disappearance of the valley at $2.88 \mathrm{eV}$ (Fig. 8) is in agreement with that of our aqueous GO solution (Fig. 1), and additional PL and PLE spectra of the water alone, measured at different energies, demonstrates a red shift in the water Raman peak (ESI, $\dagger$ Fig. S3 and S4).

Removal of trapped water and oxygen functionalities could also be observed by examining the GO samples by TGA (Fig. 9), where four weight loss peaks can be observed at 60, 190, 225 and $600{ }^{\circ} \mathrm{C}$. These peaks were attributed to loss of trapped water, easily removed hydroxyl groups, epoxide removal and less easily removed hydroxyl, and $\mathrm{C}-\mathrm{C}$ base plane decomposition, respectively. ${ }^{37}$ The first peak, at $60{ }^{\circ} \mathrm{C}$, decreased after annealing at $50{ }^{\circ} \mathrm{C}$ for $24 \mathrm{~h}$ (Fig. 9a), due to the loss of most of the trapped water. The first two peaks (60 and $190{ }^{\circ} \mathrm{C}$ ) were completely removed when annealing at $200{ }^{\circ} \mathrm{C}$ (Fig. 9c), which suggests that part of the hydroxyl functionalities are removed along with the trapped water. ${ }^{37}$ Further increasing the annealing temperature to $250{ }^{\circ} \mathrm{C}$ removes more oxygen functionalities, as indicated by the disappearance of the third

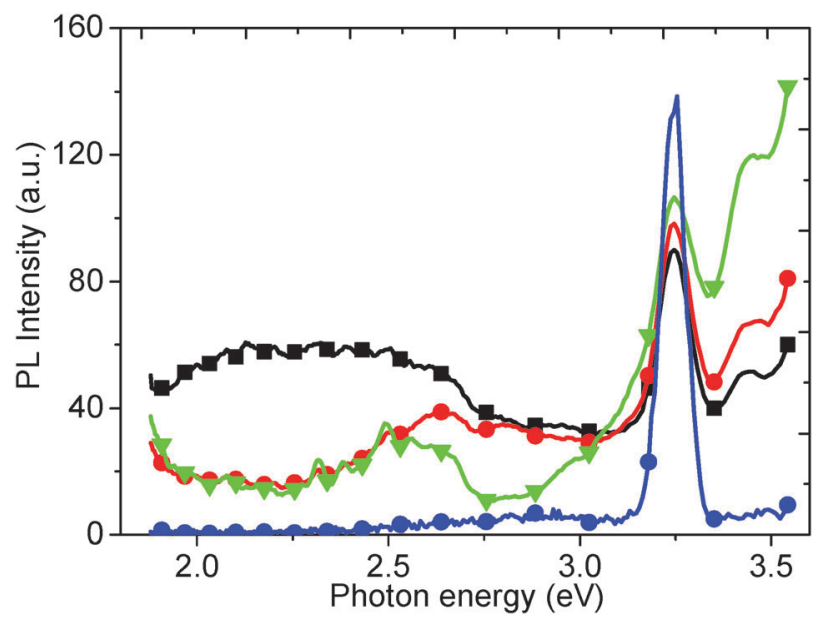

Fig. $8 \mathrm{PL}$ spectra of as-produced $\mathrm{GO}$ (black squares), and after thermal annealing at $50{ }^{\circ} \mathrm{C}$ (red circles) and $200{ }^{\circ} \mathrm{C}$ (green down triangles). The PL spectrum for water (blue circles) is also given for comparison. 


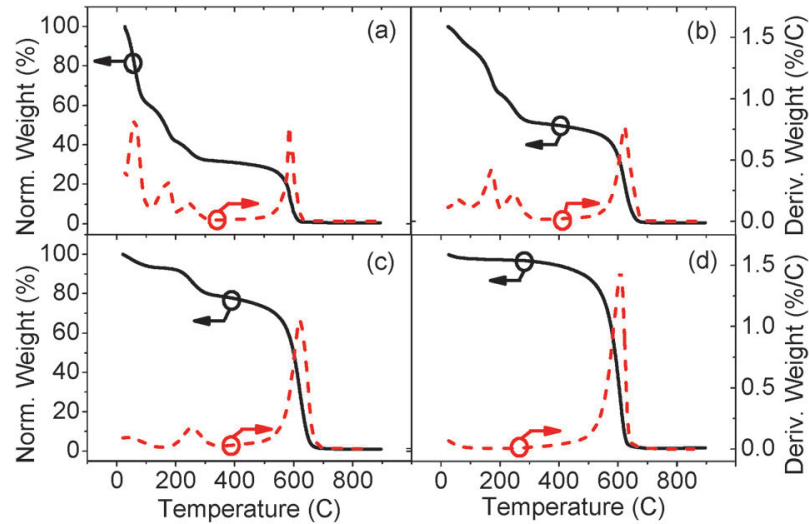

Fig. 9 TGA of (a) as-produced GO (initial weight: $13.18 \mathrm{mg}$ ), and after reduction at (b) $50{ }^{\circ} \mathrm{C}(12.47 \mathrm{mg})$, (c) $200{ }^{\circ} \mathrm{C}(12.53 \mathrm{mg})$, and (d) $250{ }^{\circ} \mathrm{C}$ (3.11 mg): normalized weight (solid black lines), derivative weight (dashed red lines).

peak at $225{ }^{\circ} \mathrm{C}$ (Fig. 9d). Comparing the differences in the PL spectra in Fig. 8 with the changes observed in the TGA data (Fig. 9), we can confirm that the $2.14 \mathrm{eV}$ peak is related to the presence of trapped water.

The TGA data is supported by XPS spectra (Fig. 10) which show the relative intensities of the $\mathrm{C}-\mathrm{C}, \mathrm{C}-\mathrm{O}$ and $\mathrm{C}=\mathrm{O}$ peaks of the GO as it is reduced. The as-produced GO has a peak intensity ratio of $1: 0.76: 0.18$ for the fitted $\mathrm{C}-\mathrm{C}, \mathrm{C}-\mathrm{O}$, and $\mathrm{C}=\mathrm{O}$ peaks respectively. After gentle reduction at $50{ }^{\circ} \mathrm{C}$, the ratio changes to $1: 0.53: 0.18$ with a noticeable reduction in the $\mathrm{C}-\mathrm{O}$ peak. Further reduction at $200{ }^{\circ} \mathrm{C}$ and $250{ }^{\circ} \mathrm{C}$ gives ratios of $1: 0.23: 0.17$ and $1: 0.24: 0.13$ respectively, suggesting a reduction in oxygen moieties on the GO surface and a subsequent increase in $\mathrm{sp}^{2}$ character in the GO.

\subsection{Effect on GO oxygen moieties}

The PLE peak (Fig. 1), and corresponding absorption shoulder (Fig. 4), at $4.02 \mathrm{eV}$ disappear when the GO is hydrothermally

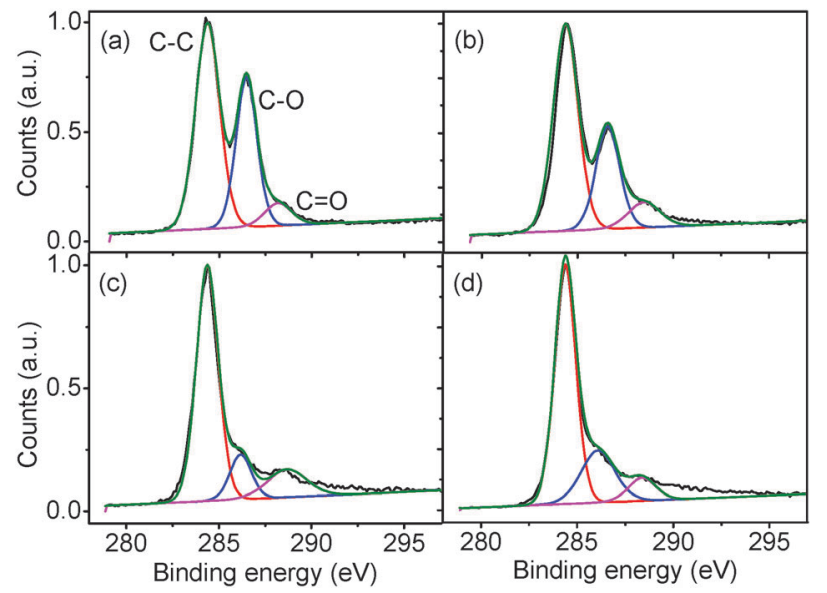

Fig. 10 XPS spectra of (a) as-produced GO, and after thermal reduction under (b) 50, (c) 200 , and (d) $250^{\circ} \mathrm{C}$ : raw data (black line), composite origin fit to spectrum (green line), and individual fits to $\mathrm{C}-\mathrm{C}$ (red line), $\mathrm{C}-\mathrm{O}$ (blue line) and $\mathrm{C}=\mathrm{O}$ (purple line) peaks.

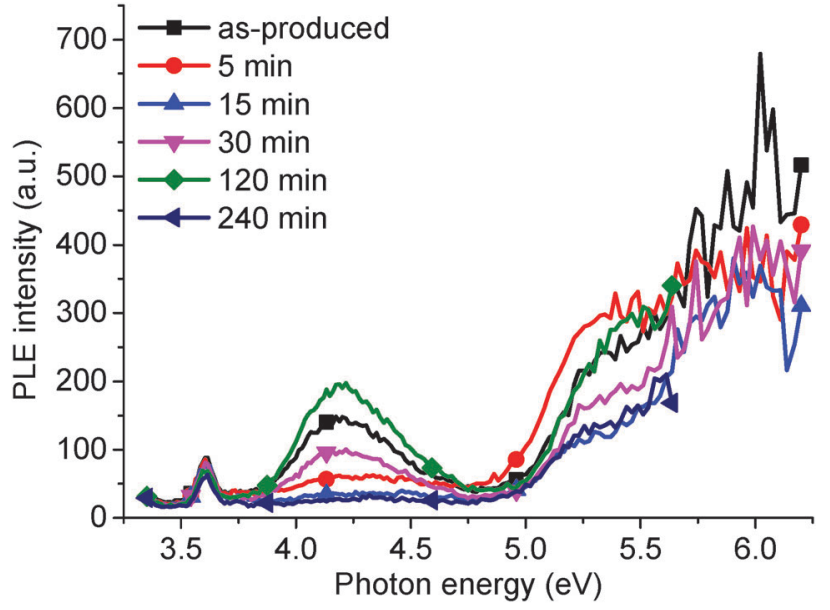

Fig. 11 PLE intensity (3.18 eV emission wavelength and $0.03 \mathrm{mg} \mathrm{ml}^{-1} \mathrm{GO}$ concentration) as a function of hydrothermal reduction time.

reduced for $240 \mathrm{~min}$ (Fig. 11), corresponding to a disappearance of the PL shoulder at $2.95 \mathrm{eV}$ (Fig. 3 and $5 \mathrm{a}$ ). Water, trapped in the GO structure, hydrogen bonds to hydroxyl and epoxide defects on the GO, ${ }^{35}$ which changes the lone electron pair density associated with the GO. With reduction, the trapped water is removed, releasing the lone electron pairs on the GO defect oxygen groups. However, as interstitial water molecules are removed, these defects, present on the surface of the GO molecules, can interact with neighboring GO molecules causing a further redistribution of the oxygen lone pairs. This causes the reduction of the corresponding absorption and PL/PLE peaks to be non-linear, unlike the reduction of the $2.14 \mathrm{eV}$ PL peak, due to the loss of the water molecules. However, with extensive reduction, for $240 \mathrm{~min}$, the PLE peak at $4.20 \mathrm{eV}$ disappears due to the removal of the oxygen groups from the GO surface. In comparison, excess $\mathrm{NaOH}$ provides abundant oxygen lone pair electrons from the additional - $\mathrm{OH}$ groups, which enhances the PL shoulder at $2.95 \mathrm{eV}$, as shown in Fig. 7a.

\subsection{Ascorbic acid reduction}

Finally, we have measured the PL of GO reduced using vitamin C (ascorbic acid). Traditionally, GO has been reduced using hydrazine hydrate however, due to the concentration of functional groups on GO that can be reduced, there is a wide variety of possible reducing agents. These range from strong, classical reducing agents, such as sodium borohydride $\left(\mathrm{NaBH}_{4}\right)$ and lithium aluminium hydride $\left(\mathrm{LiAlH}_{4}\right)$, to more exotic materials such as green tea leaf extracts, and microorganisms such as E. coli. One of the most interesting reducing agents is Ascorbic acid, also known as vitamin $\mathrm{C}$, as it can reduce to a similar extent to hydrazine, without the inherent toxicity. ${ }^{38}$ The ascorbic acid is dehydrated upon reduction of the $\mathrm{GO}^{38}$ but there are questions as to whether the ascorbic acid is consumed, or is then regenerated and participates catalytically in further GO reduction.

After reduction with ascorbic acid, the $2.14 \mathrm{eV}$ peak disappears and, in this case, a new peak is formed at $2.82 \mathrm{eV}$, potentially suggesting that the PL peak shifts from red to blue (Fig. 12). 


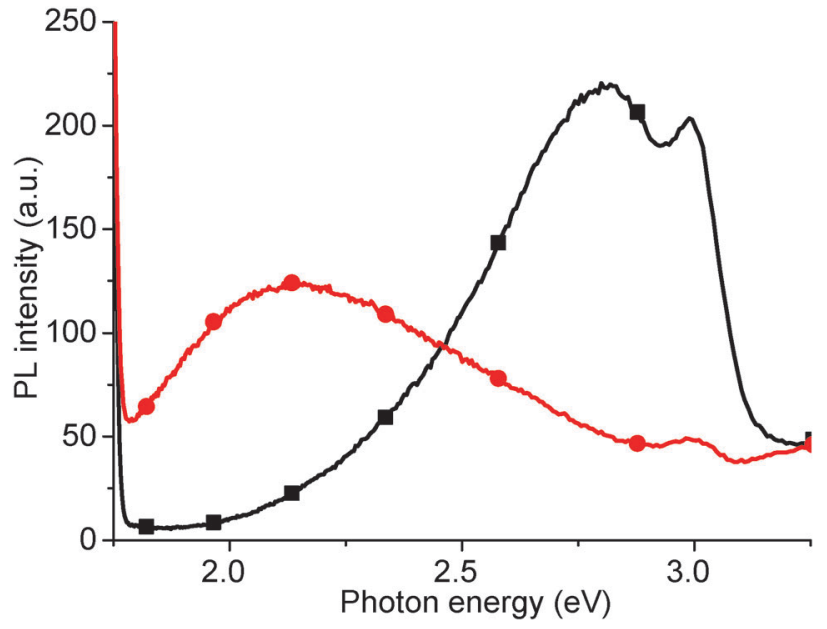

Fig. 12 PL spectrum of as-produced GO (red circles), and after room temperature reduction in ascorbic acid solution (black squares).

However, we attribute the $2.82 \mathrm{eV}$ peak after reduction to new states, induced by macro $\mathrm{sp}^{2}$ carbon sheet formation during reduction, due to recovery of the $\mathrm{sp}^{2}$ carbon network, rather than from a blue shift of the $2.14 \mathrm{eV}$ peak. ${ }^{21}$ The shoulder at $2.95 \mathrm{eV}$ is attributed to the water solvent.

\subsection{Summary}

Based on our PL experiments, a complete band structure for the hydrothermal reduction of GO can be postulated (Fig. 13), containing four bands, $\sigma, \pi$, band 1 and band 2 (Fig. 13a), corresponding to PL peaks at $4.04 \mathrm{eV}, 3.44 \mathrm{eV}$, the broad peak between 3.31 and $2.82 \mathrm{eV}$, and the $2.14 \mathrm{eV}$ peak, respectively, and which are produced by $\mathrm{sp}^{3}$ carbon, $\mathrm{sp}^{2}$ carbon, oxygen states (including lone electron pairs) and trapped water states in $\pi$ band tail, respectively. Initially during reduction, trapped water is removed, causing the $2.14 \mathrm{eV}$ peak to disappear and the 4.04 and $3.44 \mathrm{eV}$ peaks to change intensity due to variation in the $\mathrm{sp}^{3}$ hybridization content (Fig. 13b). After further reduction, the density of states in the $\sigma$ band decreases, and the density of states in the $\pi$ band increases and shift to lower energy (Fig. 13c). A new band tail due to the formation of macro size sheets of $\mathrm{sp}^{2}$ carbon is formed which contributes to the PL peak seen in the ascorbic acid reduction at $2.82 \mathrm{eV} .^{21}$ Fig. 13 also gives illustrative diagrammatic representations of the GO structure as the reduction progresses initially by losing interstitial water molecules ( $\mathrm{a}$ and $\mathrm{b}$ ) and then through the reduction of GO to rGO and the reclamation of macro sized $\mathrm{sp}^{2}$ carbon sheets (b and c).

To support the analysis of the conformational changes occurring, complementary Raman spectra of the thermally reduced GO materials have been completed (ESI, $\dagger$ Fig. S5). With the reduction of the GO, the PL background in the Raman spectra is decreased, which is consistent with our results showing similar PL reduction in the visible spectral range (Fig. 5b and 8). The D/G peak ratios also show a slight increase from 0.846 for as-produced GO to 0.868 for rGO reduced at $200{ }^{\circ} \mathrm{C}$, suggesting an increase in the $\mathrm{sp}^{2}$ character of the rGO.
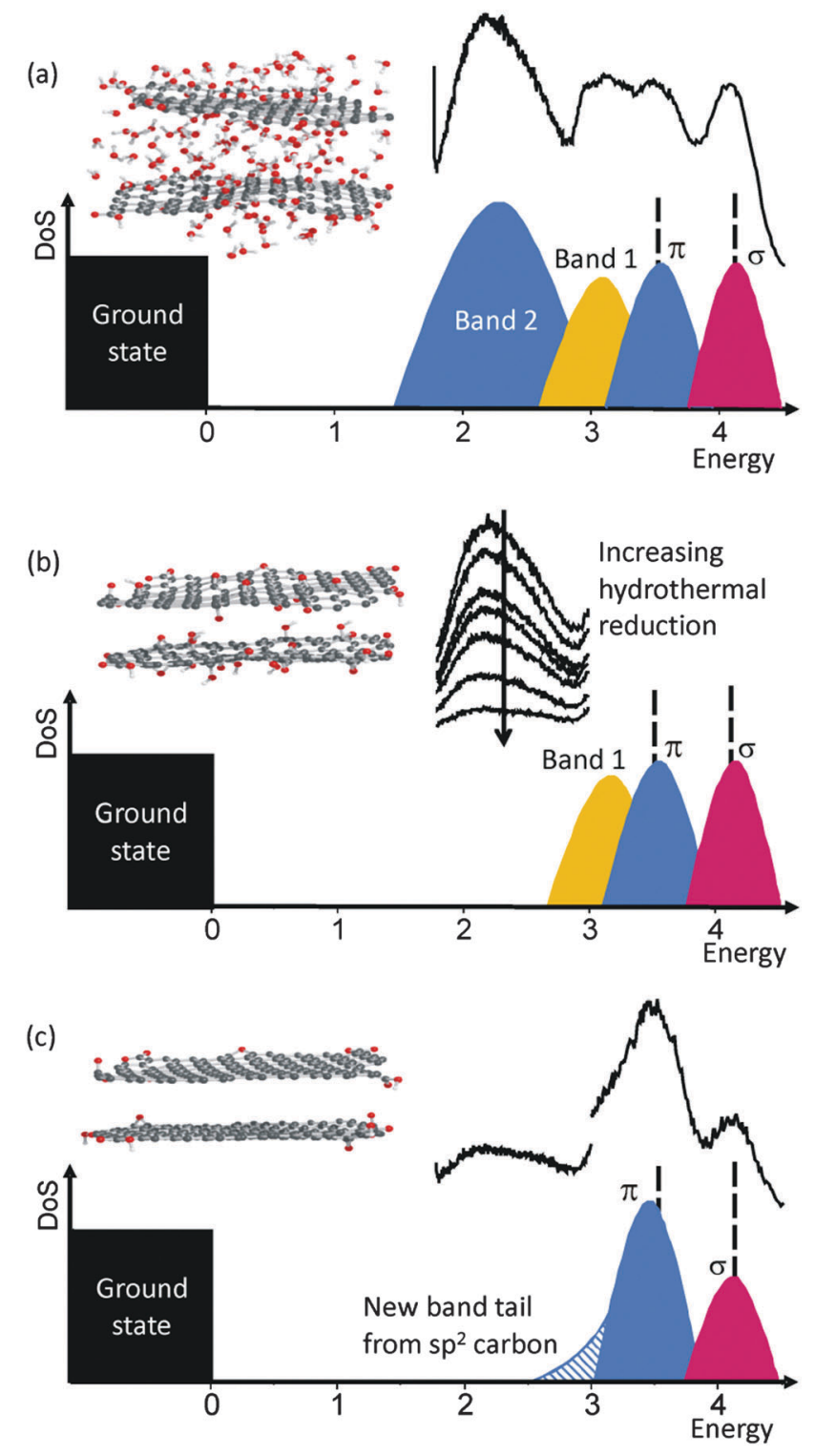

Fig. 13 Diagrammatic representations of the evolution of the chemical structure and band structure of $\mathrm{GO}$ during reduction: (a) as-produced $\mathrm{GO}$ with water intercalated GO sheets and high oxygen functionality, (b) GO with reduced intercalated water and oxygen functionality after gentle reduction and (c) reduced $\mathrm{GO}$ with minimal oxygen functionality and an increased $\mathrm{sp}^{2}$ character produced under stronger reducing conditions. The chemical structure diagrams show carbon (grey), oxygen (red) and hydrogen (white) atoms, either as part of the $\mathrm{GO}$ or as $\mathrm{H}_{2} \mathrm{O}$ molecules. For comparison in each case, the relevant PL plots are reproduced: (a) as-produced GO (from Fig. 1), (b) hydrothermally reduced at $95{ }^{\circ} \mathrm{C}$ for increasing time increments (from Fig. 5b), and (c) hydrothermally reduced at $95^{\circ} \mathrm{C}$ for $120 \mathrm{~min}$ (from Fig. $5 \mathrm{a}$ and b). Included is the experimental scale on the $x$-axis to give an idea of the positions of the bands in the diagrammatic representation (DoS $=$ density of states).

\section{Conclusions}

The current explanation of the reduction of GO, typically based on using two PL peaks, does not provide all the information required to explain the typical GO band gap (3.5 eV) or the apparent blue shift of the low energy ( $2.14 \mathrm{eV}$ ) peak. Detailed PL experiments have been completed to understand the band structure of GO, based on the 
analysis of four PL peaks at $4.04 \mathrm{eV}, 3.44 \mathrm{eV}$, a broad peak between 3.31 and $2.82 \mathrm{eV}$, and a $2.14 \mathrm{eV}$ peak, explained as being due to transitions of $\sigma-\sigma^{*}, \pi-\pi^{*}$, an oxygen states (including the lone electron pair) and a trapped water states in $\pi$ band tail, respectively. The relative intensity variation of these peaks was studied by increasing the extent of the hydrothermal reduction of the GO, and the PL measurements were supported by UV-visible and Raman spectroscopy, and TGA analysis. Based on our PL results, a complete band structure model has been postulated which outlines the changes in the density of states of the individual bands.

\section{Acknowledgements}

The authors would like to thank Violeta Doukova, Chris Buxley and John Underwood (all University of Surrey) for assistance in the production of TGA and spectroscopy data, and for technical assistance, respectively. We also acknowledge support from the Chinese Scholarship Council (grant number 201208610014), the Shannxi Youth Science and Technology Funding (grant number 2014KJXX-71), and the European Union 7th Framework Program project SMARTONICS (grant agreement number 310229).

\section{Notes and references}

1 Y. Cao, J. Zhu, J. Xu, J. He, J.-L. Sun, Y. Wang and Z. Zhao, Small, 2014, 10, 2345-2351.

2 H. Chang, Z. Sun, Q. Yuan, F. Ding, X. Tao, F. Yan and Z. Zheng, Adv. Mater., 2010, 22, 4872-4876.

3 Y. Zhu, S. Murali, W. Cai, X. Li, J. W. Suk, J. R. Potts and R. S. Ruoff, Adv. Mater., 2010, 22, 3906-3924.

4 S. Saxena, T. A. Tyson, S. Shukla, E. Negusse, H. Chen and J. Bai, Appl. Phys. Lett., 2011, 99, 013104.

5 P. Zhu, E. Cruz-Silva and V. Meunier, Phys. Rev. B: Condens. Matter Mater. Phys., 2014, 89, 085427.

6 K. D. G. I. Jayawardena, R. Rhodes, K. K. Gandhi, M. R. R. Prabhath, G. D. M. R. Dabera, M. J. Beliatis, L. J. Rozanski, S. J. Henley and S. R. P. Silva, J. Mater. Chem. A, 2013, 1, 9922-9927.

7 S. Shi, V. Sadhu, R. Moubah, G. Schmerber, Q. Bao and S. R. P. Silva, J. Mater. Chem. C, 2013, 1, 1708-1712.

8 C. T. G. Smith, R. W. Rhodes, M. J. Beliatis, K. D. G. I. Jayawardena, L. J. Rozanski, C. A. Mills and S. R. P. Silva, Appl. Phys. Lett., 2014, 105, 073304.

9 D. W. Boukhvalov and M. I. Katsnelson, J. Am. Chem. Soc., 2008, 130, 10697-10701.

10 H. Huang, Z. Li, J. She and W. Wang, J. Appl. Phys., 2012, 111, 054317.

11 A. Hunt, D. A. Dikin, E. Z. Kurmaev, Y. H. Lee, N. V. Luan, G. S. Chang and A. Moewes, Carbon, 2014, 66, 539-546.

12 Y. Luo, K.-Y. Lian, Y.-F. Ji, X.-F. Li, M.-X. Jin and D.-J. Ding, J. Phys. Chem. C, 2013, 117, 6049-6054.

13 S. Zhang, J. Zhou, Q. Wang and P. Jena, J. Phys. Chem. C, 2013, 117, 1064-1070.

14 T. Bansal, A. D. Mohite, H. M. Shah, C. Galande, A. Srivastava, J. B. Jasinski, P. M. Ajayan and B. W. Alphenaar, Carbon, 2012, 50, 808-814.
15 Z. Luo, P. M. Vora, E. J. Mele, A. T. C. Johnson and J. M. Kikkawa, Appl. Phys. Lett., 2009, 94, 111909.

16 D. A. Sokolov, Y. V. Morozov, M. P. McDonald, F. Vietmeyer, J. H. Hodak and M. Kuno, Nano Lett., 2013, 13, 5777-5784.

17 F. Liu, T. Tang, Q. Feng, M. Li, Y. Liu, N. Tang, W. Zhong and Y. Du, J. Appl. Phys., 2014, 115, 164307.

18 T. Sakthivel, V. Gunasekaran and S. J. Kim, Mater. Sci. Semicond. Process., 2014, 19, 174-178.

19 G. Eda, Y.-Y. Lin, C. Mattevi, H. Yamaguchi, H.-A. Chen, I.-S. Chen, C.-W. Chen and M. Chhowalla, Adv. Mater., 2010, 22, 505-509.

20 C.-T. Chien, S.-S. Li, W.-J. Lai, Y.-C. Yeh, H.-A. Chen, I.-S. Chen, L.-C. Chen, K.-H. Chen, T. Nemoto, S. Isoda, M. Chen, T. Fujita, G. Eda, H. Yamaguchi, M. Chhowalla and C.-W. Chen, Angew. Chem., Int. Ed., 2012, 51, 6662-6666.

21 Z. Gan, S. Xiong, X. Wu, T. Xu, X. Zhu, X. Gan, J. Guo, J. Shen, L. Sun and P. K. Chu, Adv. Opt. Mater., 2013, 1, 926-932.

22 J. R. Rani, J. Lim, J. Oh, J.-W. Kim, H. S. Shin, J. H. Kim, S. Lee and S. C. Jun, J. Phys. Chem. C, 2012, 116, 19010-19017.

23 D. Kozawa, Y. Miyauchi, S. Mouri and K. Matsuda, J. Phys. Chem. Lett., 2013, 4, 2035-2040.

24 S. K. Cushing, M. Li, F. Huang and N. Wu, ACS Nano, 2013, 8, 1002-1013.

25 X. Díez-Betriu, S. Álvarez-García, C. Botas, P. Álvarez, J. Sánchez-Marcos, C. Prieto, R. Menéndez and A. de Andrés, J. Mater. Chem. C, 2013, 1, 6905-6912.

26 C. Punckt, F. Muckel, S. Wolff, I. A. Aksay, C. A. Chavarin, G. Bacher and W. Mertin, Appl. Phys. Lett., 2013, 102, 023114.

27 A. Mathkar, D. Tozier, P. Cox, P. Ong, C. Galande, K. Balakrishnan, A. L. M. Reddy and P. M. Ajayan, J. Phys. Chem. Lett., 2012, 3, 986-991.

28 W. S. Hummers and R. E. Offeman, J. Am. Chem. Soc., 1958, 80, 1339-1339.

29 Amorphous Carbon: State of the Art, ed. S. R. P. Silva, J. Roberts and G. A. J. Amaratunga, World Scientific Press, 1998, pp. 1-374.

30 S. R. P. Silva, et al., Amorphous Carbon Thin Films, in Handbook of Thin Films, ed. H. S. Nalwa, Academic Press, 2001, ch. 9, vol. 4, pp. 403-506.

31 D. W. Lee, V. L. De Los Santos, J. W. Seo, L. L. Felix, D. A. Bustamante, J. M. Cole and C. H. W. Barnes, J. Phys. Chem. B, 2010, 114, 5723-5728.

32 A. Lerf, H. He, M. Forster and J. Klinowski, J. Phys. Chem. B, 1998, 102, 4477-4482.

33 Y. Miyajima, Y. Tison, C. E. Giusca, V. Stolojan, H. Watanabe, H. Habuchi, S. J. Henley, J. M. Shannon and S. R. P. Silva, Carbon, 2011, 49, 5229-5238.

34 Z. Luo, Y. Lu, L. A. Somers and A. T. C. Johnson, J. Am. Chem. Soc., 2009, 131, 898-899.

35 A. Buchsteiner, A. Lerf and J. Pieper, J. Phys. Chem. B, 2006, 110, 22328-22338.

36 X. Fan, W. Peng, Y. Li, X. Li, S. Wang, G. Zhang and F. Zhang, Adv. Mater., 2008, 20, 4490-4493.

37 M. J. Fernández-Merino, L. Guardia, J. I. Paredes, S. Villar-Rodil, P. Solís-Fernández, A. Martínez-Alonso and J. M. D. Tascón, J. Phys. Chem. C, 2010, 114, 6426-6432.

38 C. K. Chua and M. Pumera, Chem. Soc. Rev., 2014, 43, 291-312. 